\title{
Thiol/disulfide homeostasis as a novel indicator of oxidative stress during the treatment process of patients with septic arthritis
}

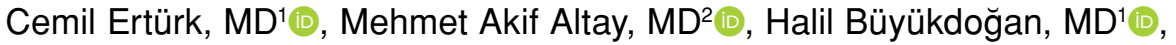 \\ Gürkan Çalışkan, $\mathrm{MD}^{1} \mathbb{1}$, Özcan Erel, $\mathrm{MD}^{3} \mathbb{B}$
}

${ }^{1}$ Department of Orthopedics and Traumatology, University of Health Sciences, Kanuni Sultan Süleyman Training and Research Hospital, Küçükçekmece, Istanbul, Turkey

${ }^{2}$ Department of Orthopedics and Traumatology, Harran University School of Medicine, Şanlıurfa, Turkey

${ }^{3}$ Department of Clinical Biochemistry, Yıldırım Beyazıt University School of Medicine, Ankara, Turkey

Septic arthritis (SA), also known as an inflammatory disease, may be a direct invasion of joint space by various microorganisms. One of the most important features of SA is synovial joint infiltration by polymorphic nuclear leukocytes and macrophages. ${ }^{[1-4]}$ These phagocytic cells respond to septic stimulation by producing reactive oxygen species (ROS).[5,6] ROS are produced by the mitochondria in aerobic cells due to increases during cell damage. ${ }^{[7,8]} \mathrm{ROS}$ are bactericidal and can cause lipid, protein and deoxyribonucleic acid lesions. ROS that increase above the physiological level cause oxidation between two-electron or redox modification of radical-based cysteine residues. ${ }^{[9]}$ In this redox reaction, the sulfur atom that is found in cysteine side chain gets oxidized

Received: October 31, 2019

Accepted: December 28, 2019

Published online: September 11, 2020

Correspondence: Cemil Ertürk, MD. SBÜ Kanuni Sultan Süleyman Eğitim ve Araştırma Hastanesi Ortopedi ve Travmatoloji Kliniği, 34303 Küçükçekmece, İstanbul, Türkiye.

E-mail: erturkc@yahoo.com

Doi: $10.5606 /$ ehc. 2020.71982

Citation: Ertürk C, Altay MA, Büyükdoğan H, Çalışkan $G$, Erel Ö. Thiol/disulfide homeostasis as a novel indicator of oxidative stress during the treatment process of patients with septic arthritis. Jt Dis Relat Surg 2020;31(3):502-508.

\section{(02020 All right reserved by the Turkish Joint Diseases Foundation}

This is an open access article under the terms of the Creative Commons Attribution-NonCommercial License, which permits use, distribution and reproduction in any medium, provided the original work is properly cited and is not used for commercial purposes (http://creativecommons.org/licenses/by-nc/4.0/).

\section{ABSTRACT}

Objectives: This study aims to investigate dynamic thiol/disulfide homeostasis as a novel indicator of oxidative stress and to find out its association with standard inflammatory markers during the treatment of patients with septic arthritis (SA).

Patients and methods: In this prospective study, a new colorimetric method for measuring thiol/disulfide homeostasis was assessed between May 2013 and October 2014 in 24 patients with SA (14 males, 10 females; mean age 14.5 \pm 19.1 years; range, 1 to 80 years) at baseline and the end of the third week of the treatment, and in 24 healthy controls (14 males, 10 females; mean age $12.5 \pm 18.7$ years; range, 1 to 85 years). Also, standard inflammatory markers such as C-reactive protein (CRP), erythrocyte sedimentation rate, and white blood cell count were evaluated.

Results: At baseline, serum disulfide was higher in SA group compared to the control group, whereas native thiol was lower $(p<0.05$ for all). At the end of the third week of the treatment, serum disulfide level was lower, whereas the native thiol was higher compared to baseline ( $\mathrm{p}<0.05$ for all). In addition, serum disulfide level was positively correlated with CRP $(r=0.736, p<0.001)$ and disulfide/native thiol ratio $(r=0.779, p<0.001)$. Furthermore, in multiple regression analyses, the disulfide level was independently associated with CRP $(\beta=0.226, p=0.005)$.

Conclusion: Our results suggest that the elevated levels of serum disulfide and standard inflammatory markers at baseline in patients with SA and decreased levels of these parameters are related with oxidative stress. This homeostasis shifted towards disulfide formation due to thiol oxidation. Therefore, thiol/ disulfide homeostasis may be a helpful biomarker for the followup in patients with SA.

Keywords: Disulfide, inflammatory markers, oxidative status, septic arthritis, thiol.

and transforms into disulfide. ${ }^{[10]}$ The formed disulfide bonds can again be reduced to thiol groups; thus dynamic thiol/disulfide homeostasis is maintained. ${ }^{[11]}$ 
Dynamic thiol/disulfide homeostasis has critical roles in antioxidant protection, detoxification, signal transduction, apoptosis, regulation of enzymatic activity and transcription factors and cellular signaling mechanisms. ${ }^{[12,13]}$ Oxidative stress is usually described as an imbalance between antioxidant defense systems and excessive reactive molecules such as ROS. Numerous studies showed that oxidative stress may have a role in the pathogenesis and/or in the progression of some musculoskeletal diseases. ${ }^{[14-17]}$

On the other hand, the diagnosis of septic arthritis can be challenging even for doctors skilled in the management of musculoskeletal disease. ${ }^{[18]}$ The important diagnostic tools are fever, refusal to bear weight and nonspecific inflammatory markers such as C-reactive protein (CRP), erythrocyte sedimentation rate (ESR), and white blood cell (WBC) count. ${ }^{[19]}$ CRP, ESR, and WBC count are very useful routine laboratory screening tests for diagnosis of a potential infection. ${ }^{[20,21]}$ In addition, these markers may monitor the course of disease in response to therapeutic intervention. Therefore, serial CRP and ESR measurements can be used as a diagnostic tool for infection, monitoring effect of treatment, or early detection of relapse. However, elevated CRP and ESR cannot show where the inflammation is located or what is causing it. Therefore, alternative adjunctive diagnostic biomarkers are needed for accurate diagnosis. ${ }^{[2,19-22]}$ To support the diagnosis, the nonspecific presentation and limited diagnostic accuracy of laboratory results often lead to an inadequate diagnosis, necessitating radiological imaging of the joint. Anteroposterior (AP)/lateral radiographs, ultrasonography and magnetic resonance imaging can increase diagnostic accuracy in patients with suspected SA. ${ }^{[2]}$

The role and importance of dynamic thiol/ disulfide homeostasis have been reported in several infectious diseases. ${ }^{[23-25]}$ Changed thiol/disulfide balances were observed in these studies. In this study, we hypothesized that oxidative stress and antioxidant defense mechanisms may play a role in the etiopathogenesis of SA. Therefore, in this study, we aimed to investigate dynamic thiol/disulfide homeostasis as a novel indicator of oxidative stress and to find out its association with standard inflammatory markers during the treatment of patients with SA.

\section{PATIENTS AND METHODS}

This prospective study was planned as descriptive research and carried out in the Department of Orthopedics and Traumatology of the Harran University Research Hospital between May 2013 and
October 2014. Twenty-four patients with SA (14 males, 10 females; mean age $14.5 \pm 19.1$ years; range, 1 to 80 years) (21 knees/three hips) and 24 age-, sex-, and body mass index-matched healthy controls (14 males, 10 females; mean age $12.5 \pm 18.7$ years; range, 1 to 85 years) were included. For inclusion into the control group, subjects must have had no known infection and inflammation symptoms. The SA diagnosis was confirmed by standardized clinical criteria and laboratory examination using Caird's criteria: fever, refusal to bear weight and non-specific inflammatory markers such as CRP, ESR, and WBC count. ${ }^{[19]}$ Blood samples were obtained at baseline and the end of the third week of the treatment. The differential diagnosis of SA included patients with any disease and other infections occurring near a joint, such as osteomyelitis, pyomyositis, septic bursitis, cellulitis, abscess or sepsis, and those who were under medication at the time of the study were excluded. The study protocol was approved by the Harran University School of Medicine Ethics Committee. A written informed consent was obtained from all of the participants and their families. The study was conducted in accordance with the principles of the Declaration of Helsinki.

Septic arthritis was considered whenever an illappearing patient with a clinical history of a traumatic limitation of mobility had the physical finding of joint irritability. All patients were initially assessed in the emergency room. At the time of presentation, the patient's temperature was documented. Physical examination was conducted in terms of inspection/ palpation and range of motion. Anteroposterior/ lateral radiographs and ultrasound were obtained for imaging evaluation. After joint aspiration, emergent synovial fluid was sent for analysis and culture in the treatment group. Then, an arthrotomy (open washout) was performed to remove all purulent fluid. Antibiotic treatment was started in the emergency room with cefazolin and continued for six weeks, intravenously during the first two weeks followed by a switch to oral treatment. The patients did not use antioxidants.

Venous blood samples were taken before the first dose of antibiotic treatment. They were separated for standard inflammatory markers and culture in the treatment group. Besides, venous blood samples were collected into empty tubes and subsequently stored on the ice at $4^{\circ} \mathrm{C}$. Blood samples were centrifugated at 1,500 rpm for $10 \mathrm{~min}$. to separate serum from blood cells. The remaining serum portions were stored at $-80^{\circ} \mathrm{C}$ until analysis.

Sodium borohydride $(\mathrm{NaBH} 4)$ is used to reduce dynamic disulfide bonds (-S-S-) to functional thiol 
groups (-SH) and formaldehyde is used to remove the unused NaBH4 remnants. This method prevents the extra reduction of 5,5'-dithiobis(2-nitrobenzoic acid) (DTNB) and the formed disulfide bond produced after the DTNB reaction. ${ }^{[26]}$ Sample's total thiol content is quantified with modified Ellman's reagent. ${ }^{[27]}$ Half of the difference, when the native thiol content is removed from the total thiol content, gives the disulfide bond amount. Serum total/native thiol concentrations and disulfide amounts were measured using an automated analyzer (Roche, Cobas c501, Mannheim, Germany).

Serum laboratory inflammation markers included serum CRP level $(\mathrm{mg} / \mathrm{dL}), \mathrm{ESR}(\mathrm{mm} / \mathrm{h})$, and WBC counts (cells $/ \mathrm{mm}^{3}$ [cells $\times 10^{9} / \mathrm{L}$ ]). C-reactive protein and WBC count were determined automatically by using biochemistry and hemogram autoanalyzers (Roche, Cobas Integra 800 Mannheim, Germany and Abbott CELL-DYN Ruby, Wiesbaden, Germany, respectively). Erythrocyte sedimentation rate was determined by the Westergren method with an autoanalyzer (Vacuplus ESR-120, Len-med, Ankara, Turkey).

\section{Statistical analysis}

Statistical analysis was performed using the IBM SPSS version 20.0 software (IBM Corp., Armonk, NY, USA). Continuous variables were expressed as mean \pm standard deviation. Chisquare test was performed to evaluate qualitative variables. Continuous variables of the patient group were compared using Wilcoxon's test. Patients and controls were compared using the Mann-Whitney $\mathrm{U}$ test. Spearman's correlation test was applied for the correlation between serum dynamic thiol/ disulfide homeostasis and inflammatory markers. Standardized B-regression coefficients and their importance obtained by multiple linear regression analysis were stated. A two-tailed $\mathrm{p}<0.05$ was considered statistically significant.

\section{RESULTS}

No statistically significant difference was observed between the patient and control groups in terms of age and sex $(\mathrm{p}>0.05)$. Patients' serum disulfide levels, disulfide/natural thiol ratio, and inflammatory markers (CRP, ESR and WBC count) were significantly higher than controls at baseline comparison $(\mathrm{p}<0.05$ for all). However, a significant decrease in native thiol values of the patients was observed $(\mathrm{p}<0.05)$ (Table I). There was no bacterial recruitment in any culture.

During the treatment, a significant decrease in disulfide levels and disulfide/native thiol ratio, CRP and WBC count of the patients were observed; however, a significant increase in native thiol levels of the patients was observed at the end of the third week of the treatment compared to baseline $(p<0.05$ for all) (Table II).

We also investigated the correlation between serum dynamic thiol/disulfide homeostasis and serum inflammatory markers and individual differences in age or sex in patients. Statistical results showed that serum disulfide level was positively correlated with

\begin{tabular}{|c|c|c|c|c|c|}
\hline Demographics & bio & $\begin{array}{l}\text { ABLE I } \\
\text { cal results of pa }\end{array}$ & is ar & & \\
\hline & (st & $\begin{array}{l}\text { atients } \\
\text { eatment } n=24 \text { ) }\end{array}$ & & $\begin{array}{l}\text { ontrols } \\
\mathrm{n}=24)\end{array}$ & \\
\hline & $\mathrm{n}$ & Mean \pm SD & $\mathrm{n}$ & Mean $\pm S D$ & $p$ \\
\hline Age (years) & & $14.5 \pm 19.1$ & & $12.5 \pm 18.7$ & $>0.05$ \\
\hline Sex & & & & & $>0.05$ \\
\hline Male & 14 & & 14 & & \\
\hline Female & 10 & & 10 & & \\
\hline C-reactive protein $(\mathrm{mg} / \mathrm{dL})$ & & $8.02 \pm 7.4$ & & $0.4 \pm 0.8$ & $<0.001$ \\
\hline Erythrocyte sedimentation rate $(\mathrm{mm} / \mathrm{h})$ & & $53.1 \pm 29.0$ & & $12.9 \pm 15.3$ & $<0.001$ \\
\hline White blood cell & & $14.6 \pm 5.2$ & & $8.9 \pm 2.5$ & $<0.001$ \\
\hline Native thiol $(\mu \mathrm{mol} / \mathrm{L})$ & & $328.5 \pm 54.3$ & & $325.0 \pm 47.4$ & $>0.05$ \\
\hline Total thiol $(\mu \mathrm{mol} / \mathrm{L})$ & & $363.2 \pm 54.1$ & & $354.0 \pm 47.4$ & $>0.05$ \\
\hline Disulfide $(\mu \mathrm{mol} / \mathrm{L})$ & & $17.3 \pm 6.7$ & & $12.6 \pm 5.6$ & $<0.05$ \\
\hline Disulfide/native thiol & & $0.05 \pm 0.02$ & & $0.03 \pm 0.01$ & $<0.05$ \\
\hline
\end{tabular}




\begin{tabular}{|c|c|c|c|}
\hline \multicolumn{4}{|c|}{$\begin{array}{c}\text { TABLE II } \\
\begin{array}{r}\text { Serum inflammatory parameters and biochemical results o } \\
\text { three weeks of treatment }\end{array}\end{array}$} \\
\hline & \multicolumn{2}{|c|}{ Patients $(n=24)$} & \multirow[b]{3}{*}{$p$} \\
\hline & Baseline & After 3 weeks of treatment & \\
\hline & Mean $\pm S D$ & Mean $\pm S D$ & \\
\hline C-reactive protein (mg/dL) & $8.02 \pm 7.4$ & $4.9 \pm 11.3$ & $<0.05$ \\
\hline Erythrocyte sedimentation rate $(\mathrm{mm} / \mathrm{h})$ & $53.1 \pm 29.0$ & $38.2 \pm 27.6$ & $>0.05$ \\
\hline White blood cell & $14.6 \pm 5.2$ & $10.5 \pm 3.0$ & $<0.05$ \\
\hline Native thiol $(\mu \mathrm{mol} / \mathrm{L})$ & $328.5 \pm 54.3$ & $365.7 \pm 71.7$ & $<0.05$ \\
\hline Total thiol $(\mu \mathrm{mol} / \mathrm{L})$ & $363.2 \pm 54.1$ & $389.6 \pm 72.2$ & $>0.05$ \\
\hline Disulfide $(\mu \mathrm{mol} / \mathrm{L})$ & $17.3 \pm 6.7$ & $11.9 \pm 4.6$ & $<0.05$ \\
\hline Disulfide/native thiol & $0.05 \pm 0.02$ & $0.03 \pm 0.02$ & $<0.05$ \\
\hline
\end{tabular}

\begin{tabular}{|c|c|c|c|c|}
\hline \multicolumn{5}{|c|}{$\begin{array}{l}\text { TABLE III } \\
\text { Relationship between serum disulfide activity and inflammatory and laboratory parameters }\end{array}$} \\
\hline & $\begin{array}{l}\text { Pearson's correlation } \\
\text { coefficient }\end{array}$ & $p$ & $\begin{array}{l}\beta \text { regression } \\
\text { coefficient }^{*}\end{array}$ & $p$ \\
\hline C-reactive protein (mg/dL) & 0.736 & $<0.001$ & 0.226 & $=0.005$ \\
\hline Disulfide/native thiol & 0.779 & $<0.001$ & 0.840 & $<0.001$ \\
\hline
\end{tabular}

CRP $(\mathrm{r}=0.736, \mathrm{p}<0.001)$ and disulfide/native thiol ratio $(\mathrm{r}=0.779, \mathrm{p}<0.001)$ before treatment. However, there was no correlation with ESR and WBC count ( $p>0.05)$ (Table III). In multiple linear regression analysis, we found that disulfide level was independently associated with CRP $(\beta=0.226, p=0.005)$.

\section{DISCUSSION}

The main results of this study were as follows. First, disulfide levels and standard inflammatory markers of the patient group were significantly higher than those of the control group in the preoperative period. Second, at the end of the third week of the treatment, serum disulfide, CRP and WBC count were lower, whereas the native thiol value was higher compared to baseline in the patient group. Third, serum disulfide levels were correlated with CRP and disulfide/native thiol ratio. Fourth, serum disulfide levels were independently correlated with CRP.

We observed a significant increase in serum disulfide values in patients with SA compared to the controls. Notably, the -SH groups of proteins are an important component of the antioxidant mechanism and the regulation of protein function through thiolbased redox switches plays an important role in the response and adaptation to local and global changes in the cellular levels of ROS. ${ }^{[26,28]}$ The plasma thiol pool is mainly formed by albumin thiols, protein thiols, and slightly formed by low-molecular-weight thiols such as cysteine, cysteinyl glycine, $\gamma$-glutamylcysteine, glutathione, and homocysteine. ${ }^{[29]}$ On the other hand, total thiol amount is formed by the combination of native thiol and disulfide amounts. The disulfide is an important indicator of oxidative-antioxidative status and disulfide bond formation is a common consequence of oxidation in cellular proteins. Disulfide bond formation, which stabilizes highgrade protein structures during protein maturation in the oxidizing environment of the endoplasmic reticulum, has been shown within various studies to be a well-established mechanism. ${ }^{[11,30]}$ However, a natural thiol is an important antioxidant cascade since it plays a role in the destruction of ROS and other free radicals with enzymatic or nonenzymatic mechanisms. ${ }^{[9-11]}$ Besides, it prevents the induction of inflammatory responses in the plasma. ${ }^{[10]}$ Therefore, we also used the native thiol activity as an antioxidant parameter. Furthermore, the thiol redox status (thiol [-SH]/disulfide [-S-S-] ratio) is a critical parameter associated with various basic biochemical processes. ${ }^{[31]}$ A recent review ${ }^{[32]}$ reported that oxidative stress-induced disulfide formation can be beneficial to cell survival. In this study, in the preoperative period, the pathogenetic mechanisms underlying the raised serum disulfide 
levels in patients with SA may be due to increased oxidative stress. Native thiol molecules can conjoin to overcome oxidative stress in the preoperative period. Erel and Neselioglu ${ }^{[26]}$ reported that patients with degenerative diseases have higher plasma disulfide levels, whereas patients with proliferative diseases have lower plasma disulfide levels. Our findings were consistent with those of their first preliminary studies. Thus, serum thiol/disulfide homeostasis can be affected by ROS in the blood, which are increased in those with SA.

At the end of the third week of the treatment, serum disulfide level was lower, whereas the native thiol level was higher compared to baseline. During the treatment process, the disulfide level again can decrease due to the disappearance of oxidative stress. Oxidative stress is physiologically related to a decrease in antioxidant defense and repair systems or an increase in the production of oxidizing agents. Therefore, the cause of the change from disulfide to native thiol (from -S-S- bond to -SH) may be due to compensatory mechanism to overcome oxidative stress in patients with SA. Thus, after appropriate treatment, organisms can heal and regain their antioxidant capacity.

We also found a significant increase in serum non-specific inflammatory markers of patients with SA at baseline compared to the controls. C-reactive protein is a major acute phase reactant and its elevated levels are caused by infections and many long-term diseases. ${ }^{[21,22]}$ Erythrocyte sedimentation rate measures inflammation or abnormal proteins in the body. ${ }^{[33]}$ In a recent review, it was demonstrated that ESR $>30 \mathrm{~mm} / \mathrm{h}$ is sensitive at an acceptable level for adult SA. ${ }^{[34]}$ It is not a predictor for any disease and commonly increases with the conditions that cause inflammation, such as infections, arthritis, or cancer. WBC count may be normal or increased in bone and joint infections. ${ }^{[33-36]}$ Caird et al. ${ }^{[19]}$ reported that a temperature above 38.5 was the best predictor of SA followed in decreasing order by CRP $>2 \mathrm{mg} / \mathrm{dL}$, ESR $>40 \mathrm{~mm} / \mathrm{h}$, difficulty in bearing weight on a limb, and serum $W B C$ count $>12,000$ cells $/ \mu L$.

In this study, at the end of the third week of the treatment, CRP and WBC count were significantly decreased in subjects with SA compared to baseline. However, ESR remained unchanged at the same time point. Various studies have reported that at the end of the appropriate treatment process, CRP increases and decreases much more quickly than ESR. C-reactive protein level rises within 6 $h$ after the onset of SA of the hip and peaks on the second day and typically returns to normal
7 to 10 days after appropriate therapy. ${ }^{[37]}$ Erythrocyte sedimentation rate continued to increase despite the active treatment until day five and it took more than a month for it to normalize. ${ }^{[36]}$

We found a relationship between the serum disulfide and CRP levels but not with ESR or WBC count. In multiple regression analysis, serum disulfide level and CRP were independently associated with SA. CRP is usually used as an inflammatory marker monitoring in predicting resolution or recurrence of bone and joint infection after a long period of posttreatment follow-up. ${ }^{[2,22,36]}$ Caird et al. ${ }^{[19]}$ performed a diagnostic level 1 prospective study concluding that a CRP $>2 \mathrm{mg} / \mathrm{dL}$ was an independent risk factor strongly associated with septic hip arthritis.

The clinical message of the current study is that thiol oxidation increased in SA patients compared to the control group. These findings may be associated with an imbalance between antioxidants and ROS, which may be a cause of the pathogenesis of articular cartilage destruction and the progression of SA. In addition, SA can often be difficult to detect clinically as blood and synovial cultures are often negative, clinical symptoms are equivocal, and laboratory results may be normal or borderline. Serum thiol/ disulfide homeostasis may be an appropriate adjunctive investigation to aid clinicians in ruling SA in or out, as well as monitoring the response to treatment. ${ }^{[38]}$ This is an important area of research as SA can have significant medical and functional consequences for patients and appropriate detection is highly desirable. Thiol/disulfide homeostasis may not be used in clinical practice as much as standard inflammatory markers, but may be an adjunct in scientific studies as an indicator of oxidative stress. Therefore, it needs to be developed in order to be used cost effectively in clinical practice.

On the other hand, patients with SA could be supported to receive an adjuvant antioxidant therapy or cysteine-rich food intake to recover the antioxidant status. It may be necessary to investigate the effect of cysteine containing supplements on the severity of SA. N-acetyl-cysteine (NAC) is widely used in patients with respiratory diseases due to its mucolytic and antioxidant activities. ${ }^{[39]}$ In addition, it has also been reported that NAC can destabilize the biofilm structure; it also has synergic action with antibiotics, and bactericidal effects. ${ }^{[40-42]}$ Thus, NAC may be an adjunct therapy option for managing SA. Therefore, this study may present the stage for further investigations of the use of antioxidant therapy as a treatment for SA. 
There could be two limitations of this study: first, the limited sample size, and second, lack of measurement of the level of native thiol and disulfide in the tissue.

In conclusion, in this study, total oxidant and antioxidant statuses were also analyzed via the dynamic thiol/disulfide homeostasis. Our results suggest that the elevated levels of serum disulfide and standard inflammatory markers at baseline in patients with SA and decreased levels of these parameters are associated with oxidative stress, as observed in several infectious diseases. This homeostasis shifted towards disulfide formation due to thiol oxidation. Therefore, thiol/disulfide homeostasis may be a helpful biomarker for the follow-up in patients with SA. To our knowledge, this is a first and preliminary study pointing out this homeostasis in SA; however, further prospective randomized clinical trials with larger sample sizes are needed to explain whether these changes are clinically significant and consistent.

\section{Declaration of conflicting interests}

The authors declared no conflicts of interest with respect to the authorship and/or publication of this article.

\section{Funding}

The authors received no financial support for the research and/or authorship of this article.

\section{REFERENCES}

1. Sharff KA, Richards EP, Townes JM. Clinical management of septic arthritis. Curr Rheumatol Rep 2013;15:332.

2. García-Arias M, Balsa A, Mola EM. Septic arthritis. Best Pract Res Clin Rheumatol 2011;25:407-21.

3. ColavitePM,SartoriA.Septicarthritis:immunopathogenesis, experimental models and therapy. J Venom Anim Toxins Incl Trop Dis 2014;20:19.

4. Atik OŞ, Ergişi Y, Ayanoğlu T, Tokgöz MA, Sezgin EA, Göçün PU. Is it easy to clinically distinguish inflammatory arthritis of bacterial origin from monoarthritis attacks of gout disease? Eklem Hastalik Cerrahisi 2016;27:167-70.

5. Papathanasiou I, Malizos KN, Poultsides L, Karachalios $\mathrm{T}$, Oikonomou $\mathrm{P}$, Tsezou A. The catabolic role of toll-like receptor 2 (TLR-2) mediated by the NF- $\kappa$ B pathway in septic arthritis. J Orthop Res 2011;29:247-51.

6. Bavunoglu I, Genc H, Konukoglu D, Cicekci H, Sozer $\mathrm{V}$, Gelisgen R, et al. Oxidative stress parameters and inflammatory and immune mediators as markers of the severity of sepsis. J Infect Dev Ctries 2016;10:1045-52.

7. Fleury C, Mignotte B, Vayssière JL. Mitochondrial reactive oxygen species in cell death signaling. Biochimie 2002;84:131-41.

8. Valko M, Leibfritz D, Moncol J, Cronin MT, Mazur M, Telser J. Free radicals and antioxidants in normal physiological functions and human disease. Int J Biochem Cell Biol 2007;39:44-84.
9. McBean GJ, Aslan M, Griffiths HR, Torrão RC. Thiol redox homeostasis in neurodegenerative disease. Redox Biol 2015;5:186-94.

10. Cremers CM, Jakob U. Oxidant sensing by reversible disulfide bond formation. J Biol Chem 2013;288:26489-96.

11. Jones DP, Liang Y. Measuring the poise of thiol/disulfide couples in vivo. Free Radic Biol Med 2009;47:1329-38.

12. Biswas S, Chida AS, Rahman I. Redox modifications of protein-thiols: emerging roles in cell signaling. Biochem Pharmacol 2006;71:551-64.

13. Circu ML, Aw TY. Reactive oxygen species, cellular redox systems, and apoptosis. Free Radic Biol Med 2010;48:749-62.

14. Altay MA, Erturk C, Aksoy N, Taskin A, Bilge A, Celik H, et al. Serum prolidase activity and oxidative-antioxidative status in Legg-Calve-Perthes disease. J Pediatr Orthop B 2011;20:222-6.

15. Altay MA, Erturk C, Aksoy N, Taskın A, Isıkan UE. A preliminary study pointing out the role of serum prolidase activity and oxidative-antioxidative status parameters during the treatment process of patients with idiopathic clubfoot. Scand J Clin Lab Invest 2011;71:576-82.

16. Ertürk C, Altay MA, Selek S, Koçyiğit A. Paraoxonase-1 activity and oxidative status in patients with knee osteoarthritis and their relationship with radiological and clinical parameters. Scand J Clin Lab Invest 2012;72:433-9.

17. Ertürk C, Altay MA, Bilge A, Çelik $H$. Is there a relationship between serum ox-LDL, oxidative stress, and PON1 in knee osteoarthritis? Clin Rheumatol 2017;36:2775-80.

18. Mathews CJ, Weston VC, Jones A, Field M, Coakley G. Bacterial septic arthritis in adults. Lancet 2010;375:846-55.

19. Caird MS, Flynn JM, Leung YL, Millman JE, D'Italia JG, Dormans JP. Factors distinguishing septic arthritis from transient synovitis of the hip in children. A prospective study. J Bone Joint Surg [Am] 2006;88:1251-7.

20. Pääkkönen M, Kallio MJ, Kallio PE, Peltola H. Sensitivity of erythrocyte sedimentation rate and C-reactive protein in childhood bone and joint infections. Clin Orthop Relat Res 2010;468:861-6.

21. Mistry RM, Lennon D, Boyle MJ, Chivers K, Frampton C, Nicholson R, et al. Septic arthritis and acute rheumatic fever in children: the diagnostic value of serological inflammatory markers. J Pediatr Orthop 2015;35:318-22.

22. Lenski M, Scherer MA. Diagnostic potential of inflammatory markers in septic arthritis and periprosthetic joint infections: a clinical study with 719 patients. Infect Dis (Lond) 2015;47:399-409.

23. Kolgelier S, Ergin M, Demir LS, Inkaya AC, Aktug Demir N, Alisik M, et al. Impaired Thiol-Disulfide Balance in Acute Brucellosis. Jpn J Infect Dis 2017;70:258-62.

24. Ozyazici S, Karateke F, Turan U, Kuvvetli A, Kilavuz H, Karakaya B, et al. A Novel Oxidative Stress Mediator in Acute Appendicitis: Thiol/Disulphide Homeostasis. Mediators Inflamm 2016;2016:6761050.

25. Walmsley SL, Winn LM, Harrison ML, Uetrecht JP, Wells PG. Oxidative stress and thiol depletion in plasma and peripheral blood lymphocytes from HIV-infected patients: toxicological and pathological implications. AIDS 1997;11:1689-97.

26. Erel O, Neselioglu S. A novel and automated assay for thiol/ disulphide homeostasis. Clin Biochem 2014;47:326-32.

27. Ellman GL. Tissue sulfhydryl groups. Arch Biochem Biophys 1959;82:70-7. 
28. Groitl B, Jakob U. Thiol-based redox switches. Biochim Biophys Acta 2014;1844:1335-43.

29. Turell L, Radi R, Alvarez B. The thiol pool in human plasma: the central contribution of albumin to redox processes. Free Radic Biol Med 2013;65:244-53.

30. Wani R, Nagata A, Murray BW. Protein redox chemistry: post-translational cysteine modifications that regulate signal transduction and drug pharmacology. Front Pharmacol 2014;5:224.

31. Chen W, Zhao Y, Seefeldt T, Guan X. Determination of thiols and disulfides via HPLC quantification of 5-thio-2nitrobenzoic acid. J Pharm Biomed Anal 2008;48:1375-80.

32. Yan LJ. Protein redox modification as a cellular defense mechanism against tissue ischemic injury. Oxid Med Cell Longev 2014;2014:343154.

33. Hariharan P, Kabrhel C. Sensitivity of erythrocyte sedimentation rate and C-reactive protein for the exclusion of septic arthritis in emergency department patients. J Emerg Med 2011;40:428-31.

34. Carpenter CR, Schuur JD, Everett WW, Pines JM. Evidencebased diagnostics: adult septic arthritis. Acad Emerg Med 2011;18:781-96.

35. Ernst AA, Weiss SJ, Tracy LA, Weiss NR. Usefulness of CRP and ESR in predicting septic joints. South Med J 2010;103:522-6.
36. Gutierrez K. Bone and joint infections in children. Pediatr Clin North Am 2005;52:779-94.

37. Kallio MJ, Unkila-Kallio L, Aalto K, Peltola H. Serum C-reactive protein, erythrocyte sedimentation rate and white blood cell count in septic arthritis of children. Pediatr Infect Dis J 1997;16:411-3.

38. Atik OŞ. Is there something new and interesting in my article? Eklem Hastalik Cerrahisi 2019;30:69.

39. Amaral EP, Conceição EL, Costa DL, Rocha MS, Marinho JM, Cordeiro-Santos M, et al. N-acetyl-cysteine exhibits potent anti-mycobacterial activity in addition to its known anti-oxidative functions. BMC Microbiol 2016;16:251.

40. Jang S, Bak EJ, Cha JH. N-acetylcysteine prevents the development of gastritis induced by Helicobacter pylori infection. J Microbiol 2017;55:396-402.

41. Göçer H, Emir D, Önger ME, Dabak N. Effects of bone cement loaded with teicoplanin, $\mathrm{N}$-acetylcysteine or their combination on Staphylococcus aureus biofilm formation: an in vitro study. Eklem Hastalik Cerrahisi 2017;28:13-8.

42. Fontes LES, Martimbianco ALC, Zanin C, Riera R. $\mathrm{N}$-acetylcysteine as an adjuvant therapy for Helicobacter pylori eradication. Cochrane Database Syst Rev 2019;2:CD012357. 